\title{
Frequency Based Analysis of Hearing Results of Cartilage Plate Myringoplasty
}

\author{
Mohamed Khamis Tolba Mahmoud Abdalla ${ }^{1}$, Mokhtar A Bassiony ${ }^{2}$, Mohamed T Aziz ${ }^{3}$ and Yasser G Shewel ${ }^{3}$ \\ ${ }^{1}$ Department of Otorhinolaryngology Head and Neck Surgery, Alexandria University, Egypt \\ ${ }^{2}$ Professor of Otorhinolaryngology, Head and Neck Surgery, Alexandria University, Alexandria, Egypt \\ ${ }^{3}$ Lecturer of Otorhinolaryngology, Head and Neck Surgery, Alexandria University, Alexandria, Egypt
}

Submission: March 06, 2017; Published: March 13, 2017

*Corresponding author: Mohamed Khamis Tolba Mahmoud Abdalla, Master of Otorhinolaryngology Head and Neck Surgery, Student of Master of Education, University Of South Wales (England), Assistant Consultant ENT National guard health affairs, KSA, Member of the Royal College of Surgeon of England , Imam Abdulrahman Al Faisal Hospital (IABFH), Dammam, Ministry of National Guard, Health Affairs, Kingdom of Saudi Arabia, Tel: 20100 4967645; Email: mokhbass@gmail.com; maziz7576@gmail.com; yassermmmm@yahoo.com

\footnotetext{
Abstract

Background: This study was conducted to determine the deferential impact of cartilage myringoplasty on hearing thresholds at different frequencies.
}

Methods: 100 patients with nearly equal variants namely, age, sex, the site and size of the perforation, and air bone gap. All cases were operated for cartilage plate myringoplasty via pot auricular and Pure Tone Audiometry as regarding $500 \mathrm{~Hz}, 1000 \mathrm{~Hz}, 2000 \mathrm{~Hz}$, and $4000 \mathrm{~Hz}$ was done three months after successful surgery.

Results: statistical analysis of hearing results and comparing them to the pre-operative counter parts then measurement of gap closure at different frequencies revealed that, myringoplasty is very effective to close gap at ( $4000 \mathrm{~Hz}$ with mean closure of $17.0 \pm 7.2$ ) followed by low frequencies $(1000 \mathrm{~Hz}, 500 \mathrm{~Hz}$ with mean closure of $11.3 \pm 3.8$ and $10.6 \pm 6.4$ respectively), then the intermediate frequency (2000 Hz with mean closure of $8.1 \pm 3.4$ ).

Conclusion: Cartilage myringoplasty reveals that middle ear mechanics are affected by weight and stiffness via the differential impact seen by this thick and stiff graft. In addition cartilage is the best to close the air bone gap at high frequencies $(4000 \mathrm{~Hz})$ and least effective if the gap is at the intermediate frequency $(2000 \mathrm{~Hz})$.

Keywords: Cartilage myringoplasty; High frequencies; Air conduction hearing thresholds; Pure tone audiometry; Deferential effect

\section{Introduction}

There are several reasons for tympanic membrane perforation, it may occur due to trauma (barotraumas, temporal bonefracture), infections (Acute otitis media, chronic otitis media, TB) and iatrogenic (ventilation tubes) [1]. Such perforation can be closed by various methods, using different graft materials such as skin, perichondrium, vein, temporalis fascia, dura and cartilage [2,3]. However many studies have compared overall hearing results of these procedures of myringoplasty; there is scarcity in researches that precisely analyze the impact of every method and graft on the different frequencies of hearing thresholds.

Detailed analysis of hearing results of cartilage plate myringoplasty at each frequency is very important because it will reveal many facts about biomechanics of the middle ear and mechanisms of hearing loss such as the impact of mass loading and change of stiffness of middle ear mechanics on hearing thresholds at different frequencies [4]. In literature, mass loading o the tympanic membrane affects the low frequency air conduction hearing thresholds up to $1000 \mathrm{~Hz}$ while increasing stiffness of the middle ear mechanisms makes the high frequency air conduction hearing thresholds to increase [5]. Cartilage plate myringoplasty adds both elements to the middle ear mechanics so that it was selected to be the target in this research [6].

It is well known, in spite of some controversies, in literature that there is no statistical difference between fascia and cartilage myringoplasty as regarding hearing results [7]. In our last study it was concluded that there was no significant difference in audiometric results between the two groups ( $p>0.05)$ despite of the large mass of the cartilage graft in comparison to the weight of fascia [8]. Consequently, neither the mass nor the stiffness of the graft in cartilage myringoplasty has any effect on hearing thresholds [6]. So that it is very important to analyze hearing results of cartilage myringoplasty in details, using highly sensitive pure tone audiometer to determine which 


\section{Global Journal of Otolaryngology}

frequencies are maximally corrected by this heavy and stiff graft. Consequently this will play a critical role in selection of the best surgical procedure; according to the configuration of the preoperative pure tone audiometry of each patient.

\section{Materials and Methods}

The study material included 100 patients, attended the outpatient clinic of the Otolaryngology-Head \&Neck Surgery Department, Alexandria Main University Hospital seeking closure of TM perforation; they were prospectively recruited to participate in the study. Study was conducted according to the guidelines of the local institutional review board and after their approval. Generally all patient were in the middle age (20-40) and they had dry central non malleular perforation for at least one month before surgery and equal air bone gap; moderate conductive hearing loss with similar configuration of PTA. All perforations were of nearly equal size; $30 \%$ of the total surface area of the TM. Participants had neither previous ear surgery nor ossicular pathology during surgery.

\section{Preoperative preparation}

a) PTA and Tympanometry were done using highly sensitive devices available at our audiology subdivision.

b) Pre-operative treatment of any wet ears and waiting for one month dry ear.

\section{Operative management}

All patients operated for cartilage myringoplasty by the same steps as the following:

a) The surgery was performed under general anesthesia. Then local infiltration of the tragus with xylocaine/ adrenaline 1:100,000 solution followed by harvesting of tragal cartilage with intact perichondrium on both sides, through a $1 \mathrm{~cm}$ incision on the posterior surface of the tragus preserving the tragal dome. The tragal incision is then closed with 4-0 polypropylene suture. Perichondrium from the side away from the external auditory canal is removed to be drape over the posterior canal wall.

b) The external auditory canal is then anesthetized using $2 \%$ xylocaine mixed with 1 in 100,000 adrenaline injection. About $1 / 2 \mathrm{cc}$ was infiltrated at (3 - o clock, 6 - o clock, 9 - o clock, and 12 - o clock) positions about $3 \mathrm{~mm}$ from the annulus; transcanal approach was used to minimize manipulation of middle ear ossicles.

c) Freshening of the margins of the perforation

d) Elevation of tympanomeatal flap: A curvilinear incision is made about $3 \mathrm{~mm}$ lateral to the annulus. This incision was extended between the 12 - o clock, 3 - o clock, and 6 - o clock positions, then skin is slowly elevated from the bone of the external canal with elevation of the annulus and incising the middle ear mucosa. Excessive manipulation of ossicles was avoided except intraoperative assessment of ossicular continuity.

e) Placement of graft (underlay technique): The cartilage graft was pushed under the tympanomeatal flap and handle of malleus. The tympanomeatal flap repositioned in such a way that it covers the free edge of the graft which has been introduced. Bits of gelfoam are placed around the edges of the raised flap. One gel foam bit is placed over the sealed perforation.

\section{Postoperative care and follow up}

a) Oral antibiotics were given for 10 days and patients were instructed not to blow the nose for one month postoperatively. They were examined with otoscope on weekly bases for the first month and antibiotic ear drops applied twice daily for 2 weeks.

b) Pure tone audiometry and tympanomertry were done three months after successful operations, using the same preoperative devices with the same calibrations.

\section{Results}

Table 1: Comparison of pre and post-operative hearing results at each frequency, and mean gap closure.

\begin{tabular}{|c|c|c|c|c|c|}
\hline \multirow{2}{*}{ Frequency } & \multirow{2}{*}{ Data from 100 case } & \multicolumn{2}{|c|}{ Air conduction hearing thresholds } & \multirow{2}{*}{$\mathbf{P}$} & \multirow{2}{*}{$\begin{array}{c}\text { Mean air bone gap } \\
\text { closure }\end{array}$} \\
\hline & & Preoperative & Postoperative & & \\
\hline $500 \mathrm{~Hz}$ & $\begin{array}{l}\text { Min. - Max. } \\
\text { Mean } \pm \text { SD } \\
\text { Median }\end{array}$ & $\begin{array}{c}25.0-50.0 \\
36.50 \pm 8.83 \\
37.50\end{array}$ & $\begin{array}{c}20.0-35.0 \\
24.0 \pm 5.68 \\
20.0\end{array}$ & $0.003^{*}$ & $10.6 \pm 6.4$ \\
\hline $1000 \mathrm{~Hz}$ & $\begin{array}{l}\text { Min. - Max. } \\
\text { Mean } \pm \text { SD } \\
\text { Median }\end{array}$ & $\begin{array}{c}20.0-40.0 \\
33.50 \pm 6.26 \\
35.0\end{array}$ & $\begin{array}{c}10.0-35.0 \\
22.50 \pm 8.25 \\
22.50\end{array}$ & $<0.001^{*}$ & $11.3 \pm 3.8$ \\
\hline $2000 \mathrm{~Hz}$ & $\begin{array}{c}\text { Min. - Max. } \\
\text { Mean } \pm \text { SD } \\
\text { Median }\end{array}$ & $\begin{array}{c}20.0-50.0 \\
29.0 \pm 10.22 \\
27.50\end{array}$ & $\begin{array}{c}10.0-35.0 \\
20.50 \pm 7.25 \\
20.0\end{array}$ & $0.009^{*}$ & $8.1 \pm 3.4$ \\
\hline $4000 \mathrm{~Hz}$ & $\begin{array}{l}\text { Min. - Max. } \\
\text { Mean } \pm \text { SD } \\
\text { Median }\end{array}$ & $\begin{array}{c}15.0-50.0 \\
30.0 \pm 11.06 \\
27.50\end{array}$ & $\begin{array}{c}10.0-40.0 \\
19.50 \pm 7.98 \\
20.024 .0 \pm 5.68\end{array}$ & $0.008^{*}$ & $17.0 \pm 7.2$ \\
\hline
\end{tabular}


$\mathrm{p}: \mathrm{p}$ value for Paired t-test for comparing between pre and post in each group.

\section{*: Statistically significant at $p \leq 0.05$.}

By use of MedCalcR - User-friendly statistical software to analyze our results, the mean preoperative air conduction hearing threshold were calculated for each frequency in all patients and compared to their counterparts in post-operative status via t- test which revealed that cartilage myringoplasty improved air conduction hearing threshold effectively at all frequencies (Table 1). Such figure also used to measure the gap closure and corrective power of the given procedure to correct the air bone gap at each frequency; it was obvious that corrective power (degree of closure of the gap) varied from frequency to another. Statistics in (Table 1) showed that the given procedure is more powerful in correcting the air bone gap at highest given frequency $(4000 \mathrm{~Hz}$ with mean closure of $17.0 \pm 7.2)$ followed by low frequencies $(1000 \mathrm{~Hz}, 500 \mathrm{~Hz}$ with mean closure of $11.3 \pm$
3.8 and $10.6 \pm 6.4$ respectively), then the intermediate frequency ( $2000 \mathrm{~Hz}$ with mean closure of $8.1 \pm 3.4$ ).

Lastly, the software was used to measure the significance of statistical difference measured in gap closure ability and to confirm that the ability of cartilage myringoplastyto close the air bone gap at certain frequencies is not due to chance so Difference, Standard error, 95\% Confidence Interval (CI), t-statistic, DF, Significance level (P) were calculated and revealed that Cartilage myringoplasty is more powerful tool to close the air bone gap at $4000 \mathrm{~Hz}$ because all ( $\mathrm{t}$ - test results; $\mathrm{p}$ values) comparing this with its counterparts at other frequencies were from $(\mathrm{p}<$ 0.00001 ) (Table 2). In addition there was statistically significant deference in air bone gap closure at $2000 \mathrm{~Hz}(\mathrm{p}<0.0001)$ in comparison to closure at all other frequencies including $4000 \mathrm{~Hz}$ which mean that cartilage myringoplasty specifically improves hearing at high frequency. However, the role of such procedure in low frequencies $(500 \mathrm{~Hz} / 1000 \mathrm{~Hz})$ was statistically insignificant.

Table 2: Detailed statistical comparison of corrective power (Gap closure) of Cartilage myringoplasty at each frequency.

\begin{tabular}{|c|c|c|c|c|c|c|}
\hline Statistical values & $500 / 1000 \mathrm{~Hz}$ & $500 / 2000 \mathrm{~Hz}$ & $500 / 4000 \mathrm{~Hz}$ & $1000 / 2000 \mathrm{~Hz}$ & $1000 / 4000 \mathrm{~Hz}$ & $2000 / 4000 \mathrm{~Hz}$ \\
\hline Difference & 0.700 & -2.500 & 6.400 & -3.200 & 5.700 & 8.900 \\
\hline Standard error & 0.744 & 0.725 & 0.963 & 0.510 & 0.814 & 0.796 \\
\hline $95 \% \mathrm{CI}$ & -0.7678 to 2.1678 & -3.9291 to -1.0709 & 4.5003 to 8.2997 & -4.2055 to -2.1945 & 4.0945 to 7.3055 & 7.3298 to 10.4702 \\
\hline t-statistic & 0.940 & -3.450 & 6.644 & -6.276 & 7.001 & 11.178 \\
\hline DF & 198 & 198 & 198 & 198 & 198 & 198 \\
\hline $\begin{array}{c}\text { Significance level } \\
(\mathrm{P})^{*}\end{array}$ & 0.3481 & $0.0007^{*}$ & $\mathrm{P}<0.0001^{*}$ & $\mathrm{P}<0.0001^{*}$ & $\mathrm{P}<0.0001^{*}$ & $\mathrm{P}<0.0001$ \\
\hline
\end{tabular}

\section{Discussion}

The main discussion in literature relies on comparison of general hearing results without taking deferential effect on different frequencies however it is well known that point wise loading of the umbo or the manubrium the region of the antro-posterior ligaments of the malleus causes predominantly deafness towards low frequencies, whereas surface loading (covering) of the pars tensa causes principally deafness towards high frequencies [9] and adding stiffness to middle ear can lead to high frequency hearing loss [6].

In this study, cartilage myringoplasty has markedly improved air conduction hearing thresholds at $4000 \mathrm{~Hz}$ followed by low frequency and intermediate frequency (2000 $\mathrm{Hz}$ ) these statistically significant differences my happen due to the impact of cartilage plate on middle ear mechanics and this enhances our knowledge bout above mentioned impact of mass and stiffness. However such results may be due to other factors such as surgeon grade, middle ear status post-operative and surgical approach, author had taken all into consideration by; one surgeon had operated the one hundred cases (specialist grade), all patients had the same middle imminence audiometer scores in post-operative follow up and the same post auricular approach was used.

\section{Conclusion}

From this large scale study it is concluded that cartilage myringoplasty is the best procedure to close air bone gapes at high frequencies thus it should be selected for those patient even fascia myringoplasty has the same overall hearing results so that this study will change decision making in in cases of perforated drum. It also reveals that Middle ear mechanics are affected by mass loading and stiffness change.

\section{Acknowledgement}

I would like to show my gratitude to Professor Mokhtar A. Bassiony, Dr. Mohamed T. Aziz (Consultant Audiologist) for sharing their pearls of wisdom with me during the course of this research. I am also immensely grateful to my patients who were the main source of data. Lastly, I want to thank my parents and my beloved wife for her great and continuous support.

\section{References}

1. Pannu KK, Chadha S, Kumar D (2011) Evaluation of hearing loss in tympanic membrane perforation. Indian J Otolaryngol Head Neck Surg 63(3): 208-213.

2. Gerber MJ, Mason JC, Lambert PR (2000) Hearing results after primary cartilage tympanoplasty. Laryngoscope 110(12): 1994-1999.

3. Couloigner V, Baculard F, El Bakkouri W, Viala P, François M, et al. (2005) Inlay butterfly cartilage tympanoplasty in children. Otol 
Neurotol 26(2): 247-251.

4. Merchant SN, Ravicz ME, Voss SE, Peake WT, Rosowski JJ (1998) Middle ear mechanics in normal, diseased and reconstructed ears. The Journal of Laryngology \& Otology 112(08): 715-731.

5. Glasscock ME, Shambaugh GE (1990) Surgery of the Ear. Saunders, Philadelphia, USA.

6. Lee CF, Hsu LP, Chen PR, Chou YF, Chen JH, et al. (2006) Biomechanical modeling and design optimization of cartilage myringoplasty using finite element analysis. Audiol Neurootol 11(6): 380-388.
7. Rosowski JJ, Merchant SN (1995) Mechanical and acoustic analysis of middle ear reconstruction. Otol Neurotol 16(4): 486-497.

8. Abdalla MKTM (2016) Effect of the weight of cartilage and fascia grafts on the audiological outcome of myringoplasty. Otorinolaringol 66: 4953.

9. Lüscher E (1945) The functional effect of loading of the tympanic membrane. Acta oto-laryngologica 33(4-5): 265-272.

Your next submission with Juniper Publishers will reach you the below assets

- Quality Editorial service

- Swift Peer Review

- Reprints availability

- E-prints Service

- Manuscript Podcast for convenient understanding

- Global attainment for your research

- Manuscript accessibility in different formats ( Pdf, E-pub, Full Text, Audio)

- Unceasing customer service

Track the below URL for one-step submission https://juniperpublishers.com/online-submission.php 